\title{
Extensive Cerebral Venous Thrombosis Secondary to Recreational Nitrous Oxide Abuse
}

\author{
Wassim Farhat $^{a} \quad$ Aaron Pariente $^{b} \quad$ Rami Mijahed $^{b}$ \\ aDepartment of Neurology and Stroke Unit, Fondation Hôpital Saint Joseph, Paris, France; \\ ${ }^{b}$ Department of Emergency, Fondation Hôpital Saint Joseph, Paris, France
}

\section{Keywords}

Cerebral venous thrombosis · Nitrous oxide recreational abuse $\cdot$ Hyperhomocysteinemia

\begin{abstract}
Nitrous oxide, colloquially known as "whippets," is a commonly abused inhalant by adolescents and young adults. There are limited data describing the adverse effects of this abuse. We present a 16-year-old girl with no medical history who presented to the emergency department for confusion, hallucinations, weakness, and headaches. Imaging revealed extensive cerebral thrombosis. She had no prior history of venous or arterial thrombosis. Hypercoagulability workup demonstrated an elevated homocysteine level. She was treated with effective anticoagulation and vitamin B12 folate supplementation. To our knowledge, there are a very few cases in the medical literature of cerebral venous thrombosis following the use of nitrous oxide. The pathophysiology of the disorder appears to be linked to the metabolism of vitamin B12 inducing hyperhomocysteinemia and a procoagulant state.

(c) 2021 S. Karger AG, Basel
\end{abstract}

\section{Introduction}

Nitrous oxide $\left(\mathrm{N}_{2} \mathrm{O}\right)$ is gaining in popularity as a recreational drug in adolescents and young adults since the last decade due to its legal access and easy availability [1]. The desired effects are euphoria and hallucination. In France, there is no specific epidemiology concerning its abuse; however, it is included in the category of inhaled recreational drugs. In a survey done in $2017,2.3 \%$ of the adults (18-64 years old) and 3.1\% younger than 17 years confirm having used one or more inhaled drugs at least once in their life [2-5].

Several adverse effects from this recreational abuse have been described including skin hyperpigmentation, subacute combined degeneration of the spinal cord, megaloblastic anemia, and bone marrow suppression [2-5], all related to dysfunction of vitamin B12 metabolism [6]. In addition, nitrous oxide inhibits the methionine synthase enzyme, leading to an increase in the blood homocysteine level, by irreversibly oxidizing the cobalt atom of vitamin B12 [7]. Hyperhomocysteinemia is considered an independent risk factor for venous thrombosis [8-11].

Nevertheless, no clear association between nitrous oxide abuse and venous thrombi was previously reported [12-15]. The present case report emphasizes the role of homocysteine in thrombotic events due to $\mathrm{N}_{2} \mathrm{O}$ abuse. 
1

Fig. 1. Brain CT: spontaneous hyperdensity at the level of the left lateral venous sinus. Fig. 2. Brain CT with IV contrast: flow void in the left lateral venous sign.

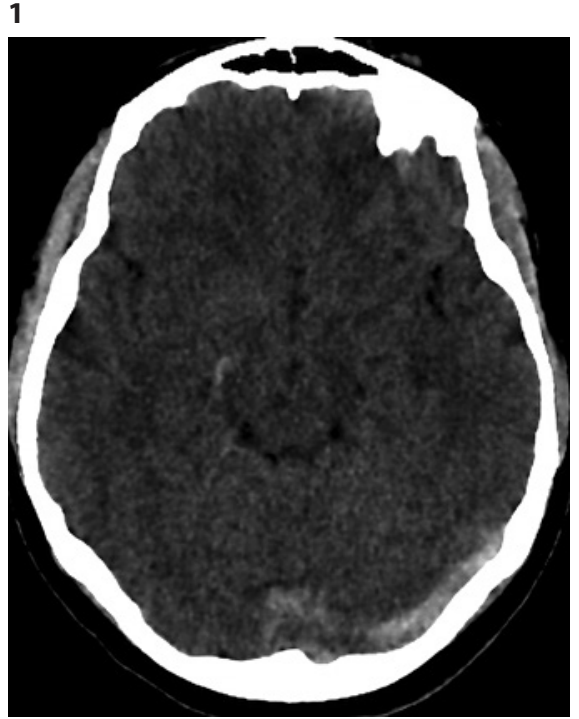

2

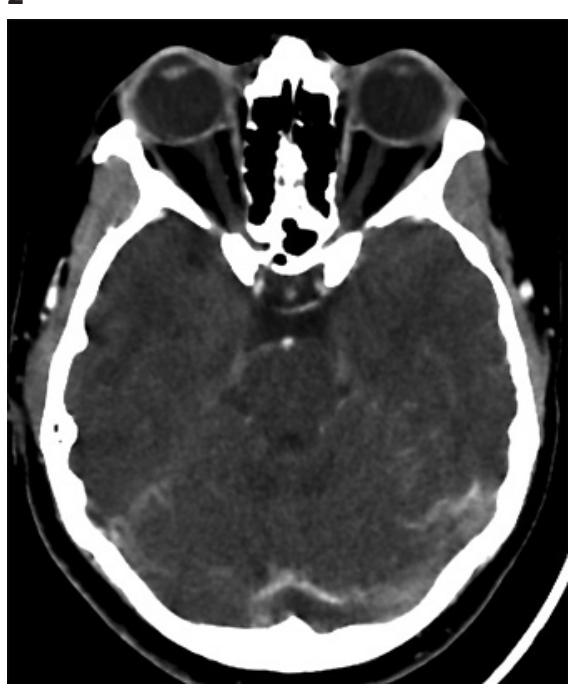

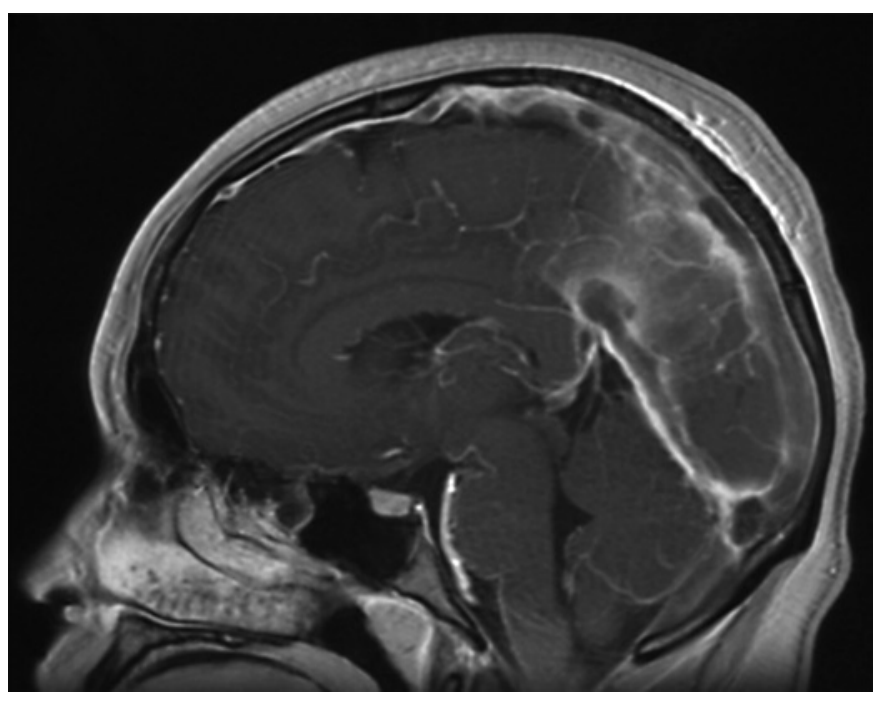

Fig. 3. Brain MRI, sagittal 3D T1 with gadolinium: flow void in the superior and inferior sagittal sinuses.

\section{Observation}

A 16-year-old girl with no previous illness was admitted to the emergency department of our institution in May 2020 for headache, lethargy, nausea, and vomiting evolving over several days. She was confined since 6 weeks, due to the SARS-CoV-2 pandemic. She admitted excessive nitrous oxide abuse for 3 weeks (up to 18 whippits per day) and denied smoking, alcohol intake, and oral contraceptive use.

At admission, her temperature was $36.7^{\circ} \mathrm{C}$, she had stiff neck, was slightly lethargic, and she had a sinus bradycardia (heart rate $46 \mathrm{bpm}$ ). Her brain CT scan was negative for parenchymal lesions but showed spontaneous hyperdensities at the level of several venous sinuses and cerebral veins. Her brain angio-CT scan confirmed the extended cerebral venous thrombosis (superior sagittal sinus, straight sinus, transverse sinuses, right sigmoid sinus, right jugular vein, and superficial and deep cerebral veins) (Fig. 1, 2). Emergency blood workup was normal, and she had negative toxic products in blood and urine. Intravenous heparin and oral acetazolamide (for relief of intracranial hypertension) were prescribed. She was then transferred to the stroke unit.

The extensive workup for thrombophilia showed vitamin B12 deficiency (93 ng/L [N: 187-883 ng/L]), normal folate levels, and a 10 -fold increase in the homocysteine level $(134 \mu \mathrm{mol} / \mathrm{L}[\mathrm{N}:<13.6$ $\mu \mathrm{mol} / \mathrm{L}])$. Protein $\mathrm{C}$, protein $\mathrm{S}$, and antithrombin III levels were normal. No mutations for the factor V Leiden and MTHFR genes were found. Antiphospholipid antibodies and viral serologies for HIV, HBV, HCV, Lyme, and syphilis were all negative, and there were no arguments for disseminated intravascular coagulation.

The lumbar puncture was not performed due to the urgency of introducing anticoagulants. Her brain MRI confirmed the extensive cerebral venous thrombosis and revealed multiple deep brain ischemic lesions and bilateral dilated optic nerve sheath (Fig. 3, 4). Her whole-body scan was positive for pulmonary embolism. Doppler ultrasound found no deep venous thrombosis at the lower limbs.

The clinical course of the patient was favorable within 10 days. Extinction of headaches and lethargy was complete. Medical treatment included anticoagulaion, and vitamin B12 and folate supplementation.

Her mental status improved over several days, and she was discharged on therapeutic dosing of low-molecular weight heparin. During the follow-up (6 months), she reported abstinence from any further drug abuse. Repeated blood workup at 3 weeks showed normalization of the homocysteine level.

\section{Discussion}

The present case is a rare presentation of $\mathrm{N}_{2} \mathrm{O}$ abuse and adverse effects. The first case of cerebral venous thrombosis associated with $\mathrm{N}_{2} \mathrm{O}$ abuse was described by Pratt et al. [15] in 2020 in a pregnant patient who had 


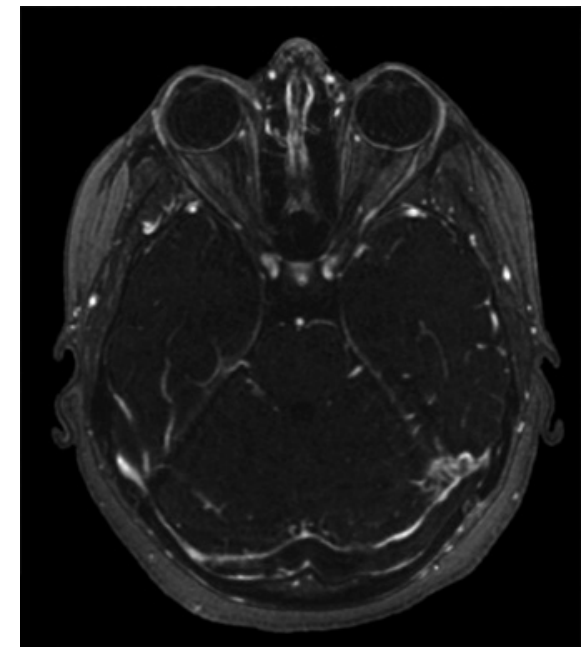

Fig. 4. Brain MRI, axial venous mask with gadolinium: flow void in the left lateral venous sign.

methylenetetrahydrofolate reductase polymorphisms. However, in our patient, we did not find any confounding factor that could increase the risk of hypercoagulability.

Toxic effects of $\mathrm{N}_{2} \mathrm{O}$ seem to be due to oxidation of the cobalt ion in vitamin B12, leading to its irreversible inactivation [7]. Vitamin B12 acts as a cofactor in the conversion of homocysteine to methionine, and its inactivation leads to accumulation of homocysteine, which prevents methylation of myelin in both the peripheral and central nervous systems. Several cases of subacute combined degeneration of the spinal cord were described with long exposure to $\mathrm{N}_{2} \mathrm{O}$ as well as acute peripheral motor and sensory neuropathy mimicking Guillain-Barré syndrome $[7,16-18]$. In these cases, the serum level of vitamin B12 is frequently low. Normal levels of vitamin B12 can also be found but falsely reassuring. Therefore, a functional vitamin B12 deficiency should be suspected and looked for by measuring the substrates of reactions catalyzed by vitamin B12, namely, methylmalonic acid and homocysteine. Some psychiatric manifestations were also described including psychotic symptoms, hallucinations, aggressive behavior, and even suicide. Cutaneous lesions with hyperpigmentation were also reported. These manifestations are also thought to be directly related to vitamin $\mathrm{B} 12$ deficiency caused by $\mathrm{N}_{2} \mathrm{O}$ abuse [2, 3, 6, 19-21].

Markedly increased homocysteine levels were associated with venous thromboembolism in 2 meta-analyses, with an odds ratio of $2.5-3[11,22,23]$.This may increase the risk of cerebral venous thrombosis. The exact mechanism is still unknown and most probably complex. It has been suspected that hyperhomocysteinemia causes endo- thelium dysfunction as well as platelet and clotting activation, impaired fibrinolysis, and a shift of the balance of methylation. In the cases previously reported, hyperhomocysteinemia was more likely to be moderate and associated with other risk factors of venous thromboembolism (pregnancy, methylenetetrahydrofolate reductase polymorphisms). In our case, the homocysteine level was 10 -fold the normal range, and no other vascular risk factor was identified.

There has been widespread recreational use of $\mathrm{N}_{2} \mathrm{O}$ in Western countries for decades, due to the fact that it is legal, cheap, and easily accessible [1]. As long as we know, there are currently no laws nor regulations to control its use.

The rapid emergence and disappearance of its euphoric effect may explain the large dose consumption reported in different studies and case reports, with serious and potentially fatal complications. Given that $\mathrm{N}_{2} \mathrm{O}$ is used in groups during parties, it could be speculated that the number of patients with mild clinical symptoms does not consult doctors.

In the CEIP report [24, 25], the recreational use of $\mathrm{N}_{2} \mathrm{O}$ in France is presented as a new public health problem due to its rapid development. However, lack of detailed knowledge on several issues remains, including the prevalence of side effects and complications.

\section{Conclusion}

This case report is an example of spectacular side effects possibly related to $\mathrm{N}_{2} \mathrm{O}$ consumption. It shows that cerebral venous thrombosis must be suspected in $\mathrm{N}_{2} \mathrm{O}$ consumers and that early treatment with anticoagulation and vitamin B12 supplementation allows favorable outcome.

\section{Statement of Ethics}

The study is exempt from ethical committee approval. This study corresponds to a case report of a patient. French research regulation (Journal Officiel de la République Française [Official Journal of the French Republic] 0160, July 13, 2018; paragraph 110 , MR-004) states that the patient's written consent is not mandatory, but investigators are required to give the patient an information leaflet explaining the purpose of the research. The patients' nonopposition to the use of their data for research was also collected in accordance with European regulations (General Data Protection Regulation). All data were extracted from our computerized medical record (Dx-Care ${ }^{\circledR}$ MEDASYS version 12.2.0.1.0). 


\section{Conflict of Interest Statement}

The authors have no conflicts of interest to declare.

\section{Author Contributions}

All authors contributed equally to the writing of this case report.

\section{Funding Sources}

No funding was required.

\section{Data Availability Statement}

Specific questions about the case can be addressed to the corresponding author.

\section{References}

1 Winstock AR. Global drug survey 2019 8th Annual Report ; 2019. Available from: https: //www.globaldrugsurvey.com/wp-content/ themes/globaldrugsurvey/results/GDS2019Exec-Summary.pdf.

2 Leslie K, Myles PS, Kasza J, Forbes A, Peyton PJ, Chan MT, et al. Nitrous oxide and serious long-term morbidity and mortality in the evaluation of nitrous oxide in the gas mixture for anaesthesia (ENIGMA)-II trial. Anesthesiology. 2015;123:1267-80.

3 Miller MA, Martinez V, McCarthy R, Patel MM. Nitrous oxide "whippit" abuse presenting as clinical B12 deficiency and ataxia. Am J Emerg Med. 2004;22:124

4 Winstock AR, Ferris JA. Nitrous oxide causes peripheral neuropathy in a dose dependent manner among recreational users. J Psychopharmacol. 2020;34:229-36.

5 Richardson PG. Peripheral neuropathy following nitrous oxide abuse. Emerg Med Australas. 2010;22:88-90.

6 Jameson M, Roberts S, Anderson NE, Thompson P. Nitrous oxide-induced vitamin B (12) deficiency. J Clin Neurosci. 1999;6:164-6.

7 Sanders RD, Weimann J, Maze M. Biologic effects of nitrous oxide: a mechanistic and toxicologic review. Anesthesiology. 2008; 109: 707-22.

8 Bienvenu T, Ankri A, Chadefaux B, Montalescot G, Kamoun P. Elevated total plasma homocysteine, a risk factor for thrombosis. Relation to coagulation and fibrinolytic parameters. Thromb Res. 1993;70:123-9.
9 Hirmerová J. Homocysteine and venous thromboembolism: is there any link? Cor Vasa. 2013;55(3):e248-58.

10 den Heijer M, Rosendaal FR, Blom HJ, Gerrits WB, Bos GM. Hyperhomocysteinemia and venous thrombosis: a meta-analysis. Thromb Haemost. 1998;80:874-7.

11 den Heijer M, Koster T, Blom HJ, Bos GM, Briet E, Reitsma PH, et al. Hyperhomocysteinemia as a risk factor for deep-vein thrombosis. N Engl J Med. 1996;334(12):759-62.

12 den Uil SH, Vermeulen EGJ, Metz R, Rijbroek A, de Vries M. Aortic arch thrombus caused by nitrous oxide abuse. J Vasc Surg Cases Innov Tech. 2018;4:80-2.

13 Sun W, Liao JP, Hu Y, Zhang W, Ma J, Wang GF. Pulmonary embolism and deep vein thrombosis caused by nitrous oxide abuse: a case report. World J Clin Cases. 2019;7:405762.

14 Bajaj D, Agrawal A, Gupta S, Bajaj S. Recreational nitrous oxide abuse causing ischemic stroke in a young patient: a rare case report. Cureus. 2018;10:e3761.

15 Pratt DN, Patterson KC, Quin K. Venous thrombosis after nitrous oxide abuse: a case report. J Thromb Thrombolysis. 2020;49:501-3.

16 Vishnubhakat SM, Beresford HR. Reversible myeloneuropathy of nitrous oxide abuse: serial electrophysiological studies. Muscle Nerve. 1991;14:22-6.
17 Flippo TS, Holder WD. Neurologic degeneration associated with nitrous oxide anesthesia in patients with vitamin B12 deficiency. Arch Surg. 1993;128(12):1391-5.

18 Brodsky JB, Cohen EN, Brown BW, Wu ML, Whitcher CE. Exposure to nitrous oxide and neurologic disease among dental professionals. Anesth Analg. 1981;60:297-301.

19 Iwata K, O’Keefe GB, Karanas A. Neurologic problems associated with chronic nitrous oxide abuse in a non-healthcare worker. Am J Med Sci. 2001;322:173-4.

20 Layzer RB, Fishman RA, Schafer JA. Neuropathy following abuse of nitrous oxide. Neurology. 1978;28:504-6.

21 Winstock AR, Ferris JA. Nitrous oxide causes peripheral neuropathy in a dose dependent manner among recreational users. J Psychopharmacol. 2020;34:229-36.

22 Ray JG. Meta-analysis of hyperhomocysteinemia as a risk factor for venous thromboembolic disease. Arch Intern Med. 1998;158: 2101-6.

23 Heijer M, Rosendaal FR, Blom HJ, Gerrits WBJ, Bos GM. Hyperhomocysteinemia and venous thrombosis: a meta-analysis. Thromb Haemost. 1998;80:874-7.

24 OFDT, Observatoire Français Des Drogues et Des Toxicomanies 2018-2019.

25 OFDT, Observatoire Français Des Drogues et Des Toxicomanies 2019-2020.
Extensive Cerebral Venous Thrombosis Secondary to Nitrous Oxide Abuse
Cerebrovasc Dis 2022;51:114-117 